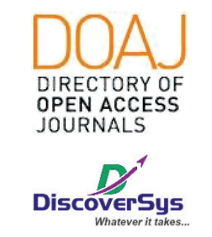

Published by DiscoverSys

\section{Microstructural aspect of pineal body: the population of pinealocytes}

\author{
Gede Wirata, ${ }^{1 *}$ Putu Nia Calista Santoso, ${ }^{2}$ Putu Ayu Utami Dewantari ${ }^{3}$
}



CrossMark

\title{
ABSTRACT
}

Background: Pineal tissue was consists of 2 cell types known as pinealocyte and astrocyte cell. Furthermore, microanatomical research of pineal body is a rare procedure conducted for several years even in Indonesia, and it was necessarily essential to reconfirm its microanatomical aspect.

Aim: This study was aimed to enrich the scope of knowledge regarding with comprehensible mammalian pinealocytes.

Methods: This study applies an observational descriptive design that describes the population of pinealocytes within the pineal body. 3 Wistar rats (Rattus novergicus), especially their pineal tissue, was extracted by carrying pinealectomy method out as a histotechnical procedure in an attentive laboratory setting. The hematoxylin-eosin
(HE) staining gives a gross feature of blue-stained nuclear cells and their environment surround them. At least, a microscopic data would be compared those samples with the previous study that had presented their electron microscopy.

Result: The characteristic of pinealocytes stained by HE are basophilic, abundant, and they have a regular nucleus. On the other side, astrocytes have longer cytoplasmic processus found around the perivascular area and among the pinealocytes one.

Conclusion: The quantities of pinealocytes appear as the most dominant cell that fills the inner part of the pineal body and probable to synchronize the production of melatonin and entirely supported by their neighbor, astrocytes.
${ }^{1}$ Anatomy Department, Faculty of Medicine, Udayana University ${ }^{2}$ Bachelor of Science Degree in Biology, Francisco J. Ayala School of Biological Sciences, University of California Irvine

3Udayana University General Hospital, Jimbaran, Bali

*Correspondence to: Gede Wirata, Anatomy Department, Faculty of Medicine, Udayana University gede.wirata@unud.ac.id

Received: 2018-01-12 Accepted: 2018-01-23 Published: 2018-01-27

Keywords: histotechnical method, pinealectomy, epiphysis

Cite This Article: Wirata, G., Santoso, P.N.C., Dewantari, P.A.U. 2018. Microstructural aspect of pineal body: the population of pinealocytes. Intisari Sains Medis 9(1): 25-30. D0I: 10.1556/ism.v9i1.151

\section{INTRODUCTION}

Nowadays, the development of medical sciences has supported us to improve the quality of human life. Those are in line with many discoveries on the treatment and prevention of various diseases. Even before the golden era over the $18^{\text {th }}$ century, there were too many figures and scientists who had contributed to recent findings of science and technology, especially the developmental knowledge about pineal gland or pineal body. The pineal gland is a gland shaped like a 'pine', a cone-shaped gland. The pineal gland is the similar name with the pineal body, the epiphysis of the cerebrum, or the "third eye" by supernatural practitioners. ${ }^{1}$ Many international studies have developed the activity of the Pineal gland, including research regarding anatomy, histology, physiology, and pharmacological roles of Pineal gland in the era before the 70s. ${ }^{2-6}$ The previous study of the pineal glands were firmly related to the neuroendocrine-reproduction axis. ${ }^{7}$ Besides, there were additional research have been explored, such as: the roles of sexual maturation, the critical role of oncological melatonin, the photoperiodic features in circadian rhythms, the vestibulosympathetic reflex, sleep mechanisms, human mood disorders, the antistressogenic mechanisms in the hypothalamus-pituitary-adrenal system, the modulation of intuition, and other functions untouched by the scientist that associated with the 'soul seat' or the third eye in spiritual phenomena as well. ${ }^{8-15}$ Also, the other discoveries concerning about the activity of the Pineal gland, such as neural pathways in the cascade of phototransduction signals, and the exploration of Pineal gland calcification as well as stimulation of solar flare. ${ }^{3}$

Of the several existing studies, the concept of internal environment within the pineal body are out of expectations. It's due to minimal study on it. Perhaps, it is hard to explore the pineal body which is still cryptic within the human brain, unless taking some advantages from an animal study. Euthanasia process makes it easily to seek the pineal compartment, especially its pinealocytes. On the other hand, pinealectomy method is not simple as many laboratory staffs can do. The method must carry out carefully as euthanized animal stay fresh and the pineal still intact. A presentation of histologically specimen would have a higher learning value for reader or another researcher as an updated scientific information, especially in classes or laboratories. It's not a nonsense topic to learn more about pinealocytes in spite of their existence is partially covered by the broad functions of melatonin. Besides, melatonin is actually produced by them. Therefore, the special pinealocytes of the 
pineal gland is necessary to be re-examined more deeply from the perspective of waking up itself to the surrounding environment. Of course, the appropriate assessment applies basic anatomical knowledge in it so that its underlying anatomy could be developed anymore due to enriching the few studies of the pineal gland in Indonesia in recent years.

\section{METHODS}

Study on the anatomical aspects of the pineal gland are carried out by cross-sectional design and are arranged as an observational microscopic design as well. The sample involves three white-colored Wistar mice (Rattus novergicus) attained the age of 3 months old and representing the internal environment of the pineal gland. Convenient laboratory facilities for their maintenance are necessary as adopts the animal's ethical clearance. Although researcher take only 3 samples, they are enough to be generalized in rodent population. They had been tried to be euthanized for pinealectomy afterward. Pinealectomy would open the path of inspection of its intact location.

The isolated pineal will then proceed with a histotechnical procedure. It automatically helps dehydration, clarification, penetration, and paraffin blocking within its. The stages are as follows: ethanol $80 \%$ is about $1 \times 0.5-2$ hours, ethanol $95 \%$ is about $4 \times 0.5-2$ hours, ethanol $100 \%$ is about $1 \times 0.5-2$ hours, xylene is about $3 \times 0.5-2$ hours, and $3 \times 0.5-2$ hours for paraffin. Next process is proceed by embedding the preparation of a paraffin-liquid in a stainless steel mold, and the top surface is sealed with a plastic cassette, and that organ is ready to be cut with a microtome, approximatelly 6 microns thickness. The ribbon-formed incision is then placed in a $45^{\circ} \mathrm{C}$ water bath. Incision by incision is then separated and captured on the object glasses prior to chrome gelatin adhesive on those. Those specimens are finally dried and ready for adding HE (Hematoxylin-Eosin) over the specimen. There is no specific measurement for cells count in spite of already microscopy features would present blue-stained nuclei over 100X magnification on them. Conventional count is eventually useful as well as inspect any compartment among them to be describe anymore.

\section{RESULT}

Of the total specimens, it was found that the pinealocytes content is hard to distinguish between types I, II, III because HE staining results are less than maximal when viewed under a light microscope (Figs. 6 and Figure 7). Depending on the intended purpose, if the researcher develops the knowledge of the distribution of the pinealocyte population, then it is best to use a light microscope (magnification $100 \mathrm{x}$ ) than the electron microscope that is more specific in scope for each cell. The distribution of pinealocytes seen under the microscope is a full-fledged distribution in the pineal body. The ridges appear to be an elongated slit line (Fig. 6) that has a total of more than 10 lines and is arranged in parallel and neat. When considered in Figure 7, it is focused on hollow spaces between blue-celled pinealocyte cells; there will be almost transparent cytoplasmic elongation between the pinealocyte populations. The concept thus emphasizes that although pineal specimen composed of two types of cells, but its internal construction ensures signals transduction system between cells according to hormonal or neuronal to respond environmental influences.

\section{DISCUSSION}

\section{Variability of Pineal Anatomy}

Characteristic of this gland is the presence of corpora aranacea build from calcification matrix (from calcium and magnesium salt). It is between two brain hemispheres, also tucked between the thalamus. It is reddish-gray as big as a pea $(8 \mathrm{~mm}$ in humans) about 150 grams in weight. ${ }^{16}$ In certain spiritual traditions, its physiological function has contributed the idea of being a bridge connecting the physical and mental responses, as well as controlling various bodily biorhythm. It works in harmony with the hypothalamus as well as directs thirst, hunger, sexual desire of the body and the biological clock that determines the process of human aging. ${ }^{17}$

There is a complex morphological variability in mammalian pineal organs, both intraspecies and interspecies. This variability reflects the specific adaptive differences of each species in the pineal function, as does the individual's response to environmental factors (e.g., annual or daily time). Of the several attempts made in the classification of anatomy, Vollrath's classification is most frequently cited (Figure 1). ${ }^{18}$ It based on the position of the organ relative to the diencephalon and the third ventricle, as well as on the pineal shape and size. Type A of pineal lies proximal to the posterior aspect of the diencephalon in direct contact with CSF (cerebrospinal fluid) in the third ventricle and through the nerve fibers of the CNS (central nervous system). On the other hand, the longitudinal pineal reaching the diencephalon toward the cerebellum classified as a proximal-intermediate-distal type (or type $A B C$ ). Between type $A$ and $A B C$, there is a type $A B$ where the length of the pineal organ increases 2 times in 


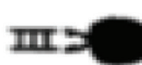

Type A

III
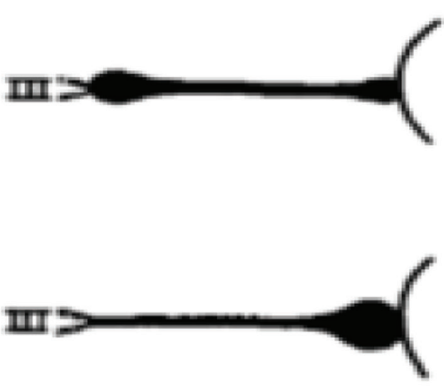

Type $\alpha \beta C$
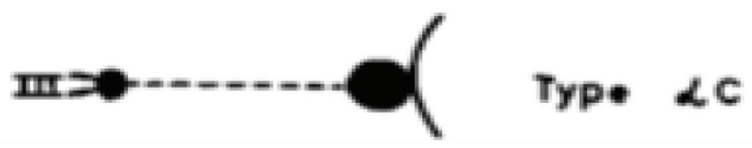

Figure 1 The illustration of mammalian pineal body ${ }^{18}$

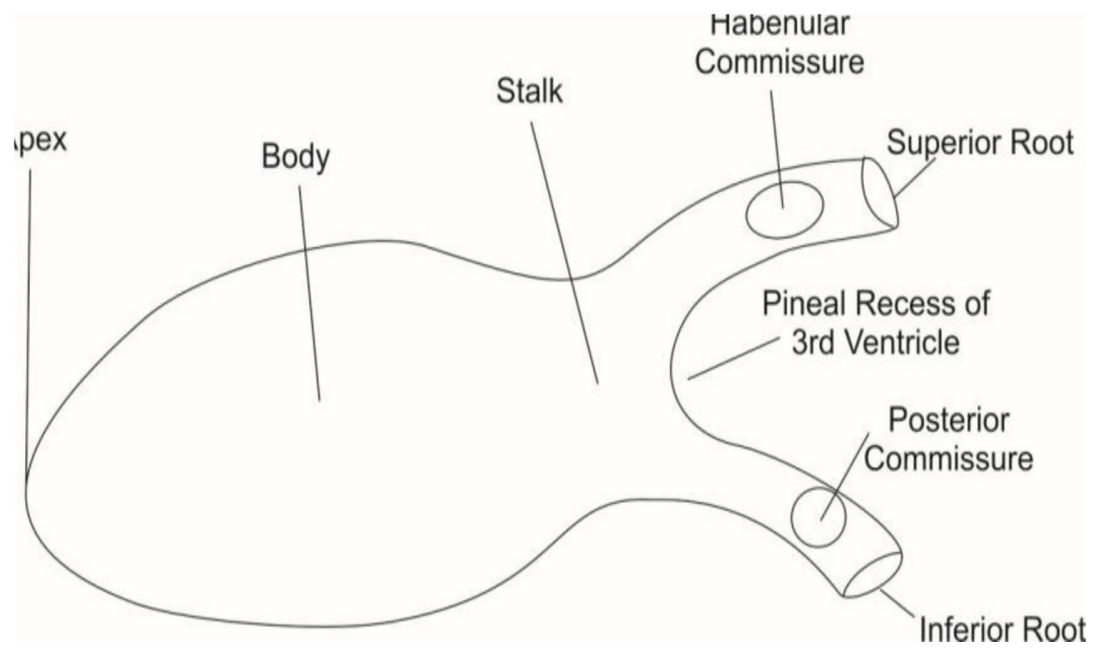

Figure 2 General microstructure of pineal body ${ }^{1}$

width. If there is shortness in the size of the pineal section, the Latin letters should replace with Greek letters. For example, the type $\alpha \beta C$ implies that the bulk or bubble size of a large pineal organ lies in the distal or superficial position, but the proximal and intermediate sections are slender. Type $\alpha \mathrm{C}$ is a characteristic that the parenchyma of pineal intermediates reduce, similar to pineal hamsters as is.

The human pineal gland is classified as type A. Its position about 1-2 $\mathrm{mm}$ from the midline makes an ideal reference point as the mid-sagittal plane. The pineal begins to develop in the second month of pregnancy - as a friction of the ependymal lining the diencephalic aspect of the third ventricle, between habenular and posterior commissure which retains a pineal stalk consisting both of the rostral and caudal lamina (Fig. 2). ${ }^{1}$ Thus, pineal (surrounded by a pial layer) is immersed in a pineal recess containing CSF, just below the splenium. The average length of the adult pineal gland is about 5-9 $\mathrm{mm}, 1-5 \mathrm{~mm}$ in width, and 3-5 mm thickness; average pineal weight in adults is about $100-180 \mathrm{mg}$, with little variation associated with age or gender.

\section{Microstructure of Pineal Gland}

Microscopically, the Pineal gland consists of two types of cells, namely: pinealocytes and astrocytes. Pinealocytes are basophilic, abundant, and they have a regular nucleus and mitochondria. These cells are in charge of producing melatonin (tryptophan derivatives). Astrocyte has a long cytoplasmic processus, is found in the perivascular area, and among pinealocytes. ${ }^{19}$ The human pineal gland is a gland with a central core consisting of lobules and cortex or edges with more distribution of neurons. Human pinealocytes have a prominent and granular nucleus appearance, with a cytoplasmic elongation that ends in the proximal peduncle and presented to the capillaries, a characteristic feature of the endocrine gland. Neuroglia (mostly astrocytes but also microglia) is distributed evenly and is usually found around the pinealocytes and in the peripheral gap. ${ }^{4}$

Meanwhile, mammalian pinealocytes do not have the ability of light sensitivity; it retains the characteristics of pineal photoreceptors found in amniotic species, reptiles and bird species, including immunoreactivity to photoreceptor-specific proteins such as rhodopsin, S-antigen, and recoverin. ${ }^{20}$ Other photoreceptor uniformity is concentration organelles (mitochondria and Golgi complexes) in the anucleus region. Lime deposits (acervuli) are the most visible radiographic characteristics in the pineal. Acervuli appears in the parenchyma tissue and the intercellular tissue as a layer hardening by calcium and magnesium salts, hydroxyapatites, and trace elements. Deposits of granular lime appear from birth, but their density increases with age, persisting in young adulthood. Radiographic studies have failed to show a correlation between the level of calcification and the function of secretions. However, the calcification density detected by CT scan could be used for estimates the size of the functional tissue, which has been reported to be negatively correlated with age and the incidence of chronic daytime sleepiness and sleep disturbances. Glial and benign ependymal 

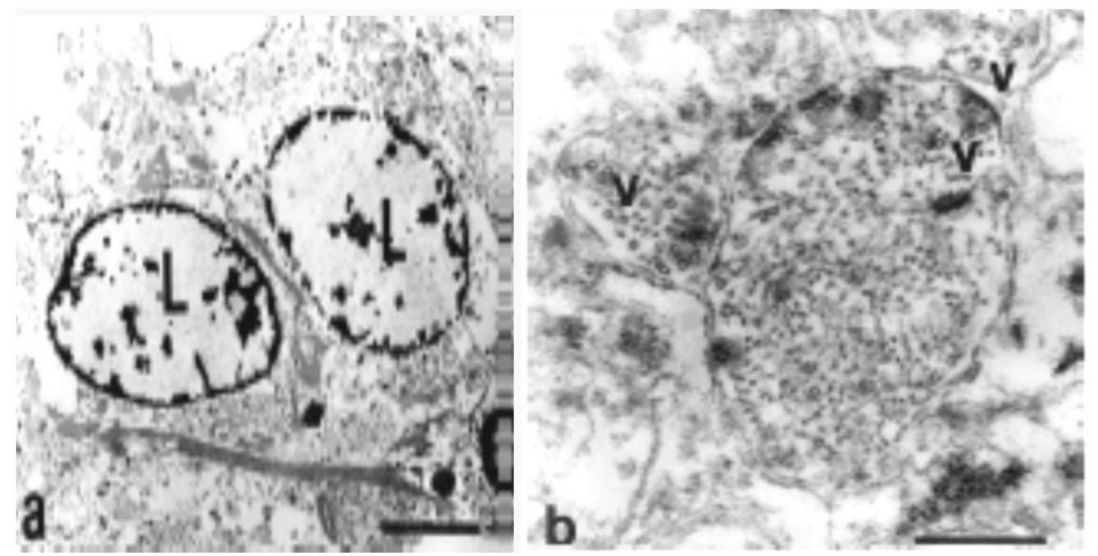

Figure 3 Type I pinealocytes. (a) Regular nucleic membranes without nuclear folds in type I pinealocytes (L); (b) Vesicle (V) in the elongation and terminal of the pinealocyte cell cytoplasm of type $\mathrm{I}^{4}$


Figure 4 Electron micrographs on pinealocyte cell type II ( $a$ and $b$ ). The folding of the nuclear membrane with some rough RE (thin arrows) and cytoplasmic pigments (thick arrows) invaginates to form the folds of the nucleus ${ }^{4}$
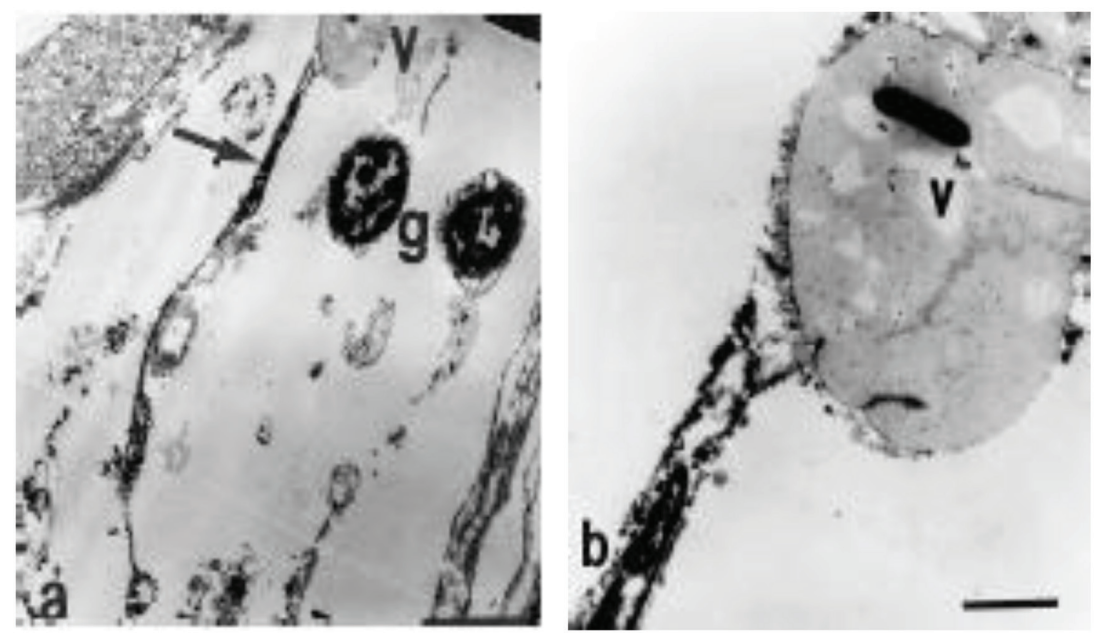

Figure 5 Electron micrographs on pinealocyte cell types III ( $a$ and b). Type III cells have very different sizes and morphologies with types I and II and surrounding glial cells (g). At the end of the cell type III emerges a vacuole (enlarged on $\mathrm{b})^{4}$ cysts (rare frequencies) are often observed and can cause morphological and functional degradation of the pineal tissue.

\section{PINEALOCYTE CELLS TYPE}

The population of pinealocytes was determined by their cell size and nucleus, nuclear lobule, cytoplasmic content and dye density, so that 3 histologic types of pinealocyte found, i.e. ${ }^{4}$

\section{Type I Pinealocytes (light pinealocytes)}

Type I Pinealocytes are the principal cells in the mammalian pineal gland, both children, and adults (Fig. 3). The cells are round or oval with an average diameter range of 7 to $11 \mu \mathrm{m}$. The nucleus is oval or round also with an average diameter range of $5.8 \mu \mathrm{m}$ and has a non-folding membranous wall of membranes on a regular basis. There is also a condensation of chromatin material on the inner surface of the nuclear sheath. This cell contains vesicles on the elongation and cytoplasmic terminals.

\section{Type II Pinealocytes (dark pinealocytes)}

Type II pinealocytes are oval or rounded in length with an average diameter range of 7 to $12 \mu \mathrm{m}$ (Figure 4). The nucleus is irregular and large with a diameter range of $6.4 \mu \mathrm{m}$. Some nuclear membrane folds are found with the aid of a light microscope as well as an electron microscope. There is invagination on the part of the cytoplasm that enters the nuclear folds, so there is a nuclear pellet under the examination of the light microscope. The pellet is best viewed by double coloring (light green and acid fuchsin). In this staining, the type II pinealocyte nucleus forms the appearance of a dark solid like a sponge that overlaps with its cytoplasm. There is also a condensation of chromatin material on the inner surface of the nuclear sheath. The cell cytoplasm of type II pinealocytes contains many pigments that can be seen in the folds of their nuclei; even some rough RE can be seen clearly in the invasion of the cytoplasm into the nuclear fold.

\section{Type III Pinealosit}

Unlike the case with the two pinealocytes mentioned above, some other cells can be seen with the characteristics of the cell body and its elongated and thin cell nucleus (Figure 5). The longest cell diameter ranges from 12 to $32 \mu \mathrm{m}$, and the shortest diameter ranges from 0.5 to $1.4 \mu \mathrm{m}$. The nucleus almost fills this type III cell space and leaves some space for its cytoplasm. The longest diameter of the nucleus ranges from 8 to $20 \mu \mathrm{m}$, and the shortest diameter ranges from 0.4 to $1.3 \mu \mathrm{m}$. These cells almost always produce a vacuole containing a liquid material and accumulated secretions of material to 


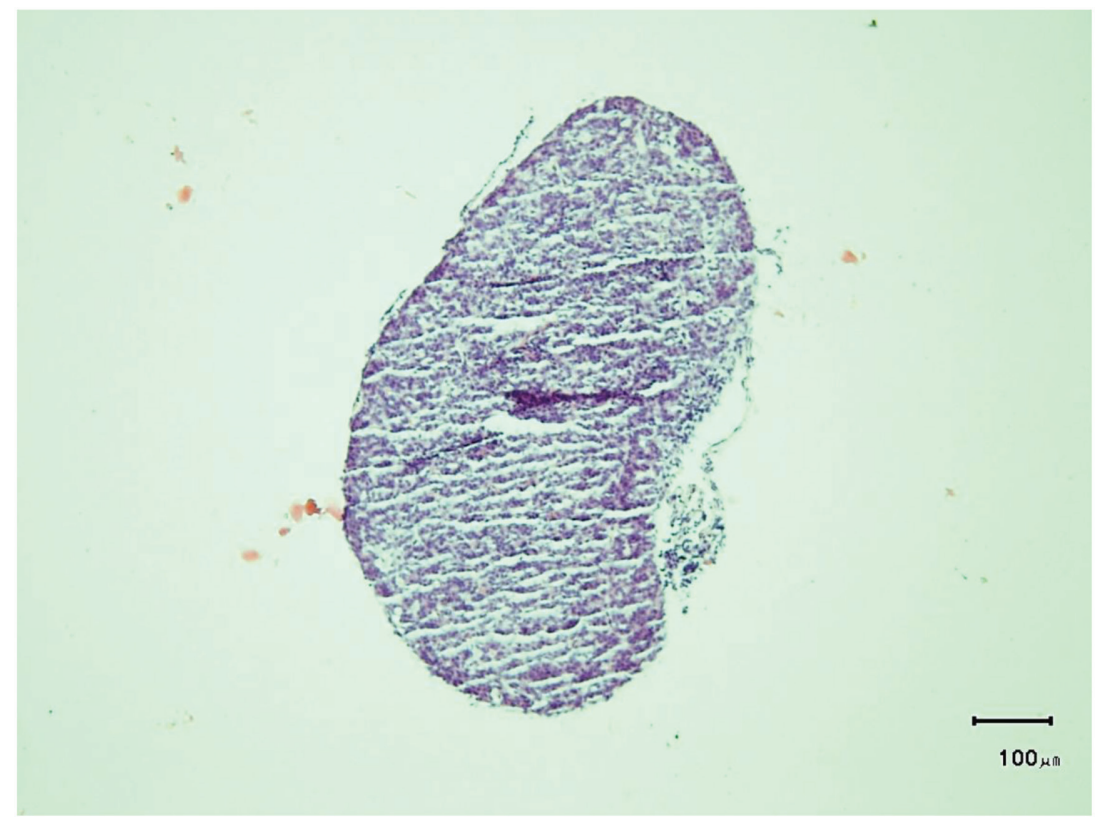

Figure 6 Photograph of light micrographs on pinealocyte cells that fill the pineal body space (magnification 40x) with a size range of $900 \mathrm{x}$ $450 \mu \mathrm{m}$. There are long, parallel white lines that divide the placement of pinealocytes and astrocyte

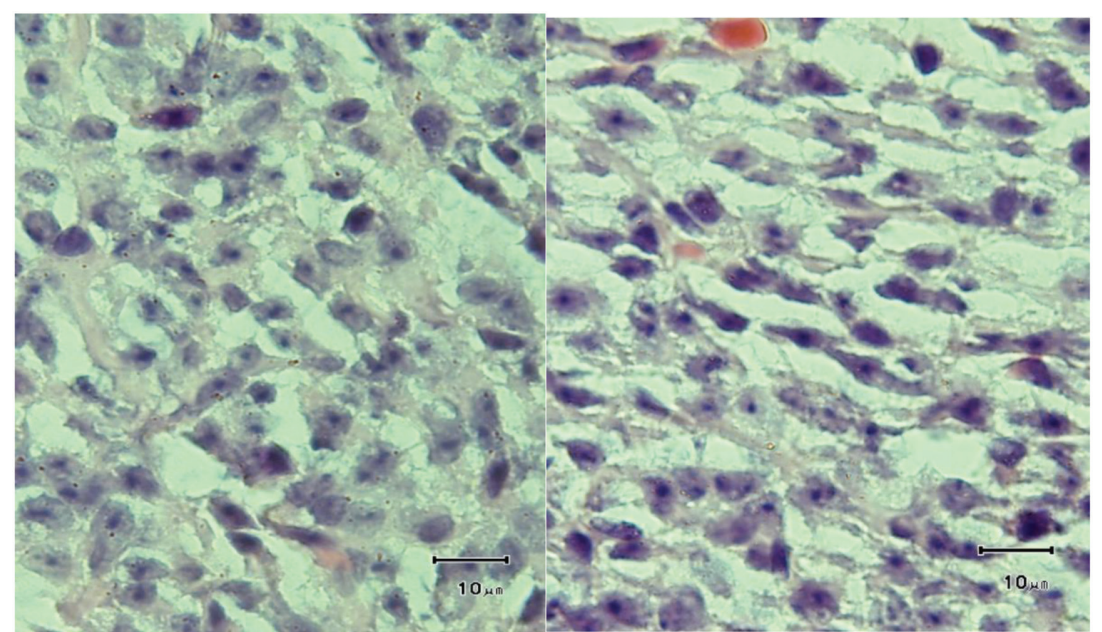

Figure 7 Microscopic photos of pinealocyte cells that fill the pineal body space (100x magnification). The appearance of purplish-colored cells is some basophilic pinealocytes, large size, and cytoplasm. The pinealocyte nuclei appear like a dark purple. Among them are astrocytes spreading that make the body of the pineal closer each other

form an extracellular compartment. The typical characteristic of this type III cell distinguishes it from type I, type II and astrocytes. ${ }^{4}$

\section{CONCLUSION}

Pinealocyte population does not only expresses their component themselves within the pineal gland, but also astrocytes are surrounding them that support their functional life. Almost pinealocytes appear to make inner part of pineal gland more overload, even though many parallel gaps or rifts make unique microstructure feature of the pineal gland as is.

\section{CONFLICTS OF INTEREST}

The author states there is no conflict of interest regarding the presumption of innocence in the research report.

\section{ACKNOWLEDGEMENT}

On this study, the authors would like to acknowledge Mr. Dewa Witana as a technician in Veterinary Laboratory Faculty of Veterinary Medicine Udayana University, which has provided input and direction in the process of specimen work and to Mr. drh. Ely, the Veterinary Center staff who have helped microscopic measurements.

\section{REFERENCES}

1. Sahai A. Pineal Gland History \& Lesser Known Facts [powerpoint]. India: King George's Medical Faculty; 2011.

2. Axelrod J. The Pineal Gland: A Neurochemical Transducer [Artikel]. Science 1974; 184 (Issue 4144): 1341-8

3. Standering S. "Ventricular System \& Subarachnoid Space," chapter 10, pp. 240-241, "Diencephalon," chapter 21, p. 324, “The Nervous System" chapter 24, p. 380, "Eye," chapter 40, p. 692. In: Gray's Anatomy: The Anatomical Basis of Clinical Practice. 40th ed. Churchill Livingstone: Elsevier; 2008 .

4. Husain SMA. The Pinealocytes of the Human Pineal Gland: A Light and Electron Microscopic Study. Folia Morph 2006; 65 (3): 181-7

5. Wurtman RJ and Julius Axelrod. The Pineal Gland. Massachusetts Institute of Technology; 2013. [Accesed on: 18 February 2017] URL: http://wutrmanlab.mit.edu/static/ pdf/40.pdf

6. Srinivasan V. The Pineal Gland: Its Physiological and Pharmacological Role [Review Article]. Ind. J. Physiol. Pharmac 1989; 33 (No. 4): 263-72

7. Manca ME, Manunta ML, Spezzigu A, Torres-Rovira L, Gonzales-Bulnes A, Pasciu V, et.al. Melatonin Deprivation Modifies Follicular and Corpus Luteal Growth Dynamics in a Sheep Model. Reproduction 2014; 147: 885-95

8. Olcese J. Melatonin Receptors in The Human Reproductive Tract [Article]. [Puiblisher unknown]; 2007; 47-56. URL: https://www.yumpu.com/en/document/view/17620359/ melatonin-receptors-in-the-human-reproductive-tract

9. Cutando A, Lopez-Valverde A, Arias-Santiago S, Vicente JD, De Diego RG. Role of Melatonin in Cancer Treatment [Review]. Anticancer Research 2012; 32: 2747-54

10. Renzi A, Glasser S, DeMorrow S, Mancinelli R, Meng F, Franchitto A, et.al. Melatonin Inhibits Cholangiocyte Hyperplasia in Cholestatic Rats by Interaction with MT1 but not MT2 Melatonin Receptors. Ann J Physiol Gastrointest Liver Physiol 2011; 301: 634-43

11. Han Y, DeMorrow S, Invernizzi P, Jing Qi, Glaser S, Renzi A, et.al. Melatonin Exerts by an Autocrine Loop Antiproliferative Effects in Cholangiocarcinoma; Its Synthesis is Reduced Favoring Cholangiocarcinoma Growth. Ann J Physiol Gastrointest Liver Physiol 2011; 301: 623-33

12. Zats M, Gastel JA, Heath III JR, Klein DC. Chick Pineal Melatonin Synthesis: Light and Cyclic AMP Control Abundance of Serotonin N-Acetyltransferase Protein. J. Neurochem 2000; 74: 2315-21 
13. Zhang B-L, Zannou E, Sannajust F. Effects of Photoperiod Reduction on Rat Circadian Rhythms of BP, Heart Rate, and Locomotor Activity. Am J Physiol Regulatory Integrative Comp Physiol 2000; 279: 169-78

14. Cook JS, Chester AR. Melatonin Attenuates The Vestibulosympathetic but not Vestibulocollic Reflexes in Humans: Selective Impairment of the Utricles. J Appl Physiol 2010; 109: 1697 - 1701

15. Purucker G. Man in Evolution. Chapter $16^{\text {th }}$. The Pineal and Pituitary Glands. Theosophical University Press; 2011: 208.

16. Lokhorst GJ. Descartes and the Pineal Gland. USA: Stanford Encyclopedia of Philosophy; 2013. [Accesed on 7 March 2017] URL: https://plato.stanford.edu/entries/ pineal-gland/

17. Vollrath L. Comparative Morphology of the Vertebrate Pineal Complex. Dalam Kappers JA, Pevet P, editor. The Pineal Gland of Vertebrates Including Man [e-book]. Elsevier: Progress in Brain Research; 2011: Vol 53: 25-38

18. cappersMiline R. Different Populations of Pinealocytes in the Pineal Gland of the Mole-Rat (Spalax leucodon,
Nordmann). In: Kappers JA, Pevet R, editor. The Pineal Gland of Vertebrates Including Man [e-book]. Elsevier: Progress in Brain Research; 2011: Vol 53: 207-12

19. Kappers JA. The Pineal Organ: An Introduction. Dalam Wiley J dan Sons, editor. The Pineal Gland. CIBA Foundation Symposium: Novartis Foundation Symposia; 2009: 3-26

20. Hodde KC. The Vascularization of the Rat Pineal Organ. In: Kappers JA, Pevet P, editor. The Pineal Gland of Vertebrates Including Man [e-book]. Elsevier: Progress in Brain Research; 2011: Vol 53: 39-44

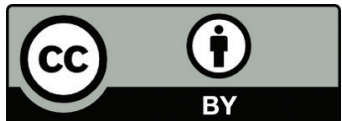

This work is licensed under a Creative Commons Attribution 